\title{
Spider phobia is associated with decreased left amygdala volume: a cross-sectional study
}

\author{
Melanie S Fisler ${ }^{1 *}$, Andrea Federspiel ${ }^{1}$, Helge Horn ${ }^{1}$, Thomas Dierks ${ }^{1}$, Wolfgang Schmitt ${ }^{1}$, Roland Wiest ${ }^{2}$, \\ Dominique J-F de Quervain ${ }^{3}$ and Leila M Soravia ${ }^{1}$
}

\begin{abstract}
Background: Evidence from animal and human studies imply the amygdala as the most critical structure involved in processing of fear-relevant stimuli. In phobias, the amygdala seems to play a crucial role in the pathogenesis and maintenance of the disorder. However, the neuropathology of specific phobias remains poorly understood. In the present study, we investigated whether patients with spider phobia show altered amygdala volumes as compared to healthy control subjects.
\end{abstract}

Methods: Twenty female patients with spider phobia and twenty age-matched healthy female controls underwent magnetic resonance imaging to investigate amygdala volumes. The amygdalae were segmented using an automatic, model-based segmentation tool (FSL FIRST). Differences in amygdala volume were investigated by multivariate analysis of covariance with group as between-subject factor and left and right amygdala as dependent factors. The relation between amygdala volume and clinical features such as symptom severity, disgust sensitivity, trait anxiety and duration of illness was investigated by Spearman correlation analysis.

Results: Spider phobic patients showed significantly smaller left amygdala volume than healthy controls. No significant difference in right amygdala volume was detected. Furthermore, the diminished amygdala size in patients was related to higher symptom severity, but not to higher disgust sensitivity or trait anxiety and was independent of age.

Conclusions: In summary, the results reveal a relation between higher symptom severity and smaller left amygdala volume in patients with spider phobia. This relation was independent of other potential confounders such as the disgust sensitivity or trait anxiety. The findings suggest that greater spider phobic fear is associated with smaller left amygdala. However, the smaller left amygdala volume may either stand for a higher vulnerability to develop a phobic disorder or emerge as a consequence of the disorder.

Keywords: Spider phobia, Amygdala, Morphology

\section{Background}

Specific phobias are characterized by automatic, exaggerated fear responses towards phobia-specific objects [1]. Converging evidence implies the amygdala as the most critical structure involved in processing of phobia-relevant, but also general threatening stimuli [2-6]. Through its broad connections to other brain areas, it might be involved in mediating automatic responses to potential danger [7]. Due to its projections to the visual stream, it is further likely to

\footnotetext{
* Correspondence: melanie.fisler@puk.unibe.ch

'Department of Psychiatric Neurophysiology, University Hospital of Psychiatry, University of Bern, Bolligenstrasse 111 3000, Bern 60, Switzerland Full list of author information is available at the end of the article
}

modulate sensory processing [8]. In contrast to large functional imaging evidence for the involvement of the amygdala in fear, there have been few reported studies on its structural abnormality in mood and anxiety disorders [9-12]. Reduced amygdala volume (AMV) has been reported to be significantly correlated with the severity of distortion in anxiety $[13,14]$ and panic disorder [15]. Structural brain imaging studies in specific phobia are lacking. This raises the question whether functional differences in phobic patients appear in association with structural differences. Because of evidence of hyperactivity and structural differences in anxiety disorders, we hypothesized that also spider phobic patients (SP) express reduced AMV compared to healthy

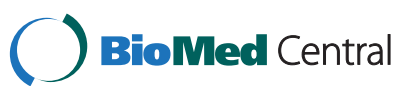


controls. Phobic fear may be characterized by a combination of physiological and behavioral components. In order to clarify the contribution of possible confounding factors, several aspects of phobic disorders that could be critical to the pathogenesis have to be considered. Anxiety-related personality traits have been suggested to represent important predisposing factors for anxiety-related disorders [16,17]. Other potential moderating variables may be the severity and duration of the disease and disgust sensitivity. Therefore, the association between AMV and several clinical features has been investigated in this study. To the best of our knowledge, this is the first study investigating volumetric differences of the amygdala in SP compared to healthy control subjects.

\section{Methods}

\section{Subjects}

Twenty female patients with a current diagnosis of spider phobia and twenty healthy female controls matched for age were included in the analysis. Subjects were recruited via advertisements. The data used for this report has been collected in a larger project investigating the effect of cortisol on the outcome of an exposure-based short-term group therapy for spider phobia. Because the study design included an exposure task and in order to minimize motion artifacts, only patients that could keep still while facing a picture of a spider were included in the magnetic resonance paradigm. Exclusion criteria for patients were the following: any axis I other than specific phobia for spiders, axis II disorders, the manifestation of acute or chronic medical condition, neurological diseases, current drug or alcohol abuse or any contraindication to magnetic resonance imaging (metallic objects, pregnancy) or confounding factors for structural brain studies (regular medication, contraceptives, left handedness). Healthy control subjects were excluded from the study if they met any of the following exclusion criteria: axis Idisorders (measured with the SCL-90-R), the manifestation of acute or chronic medical condition, neurological diseases, current drug or alcohol abuse or any contraindication to magnetic resonance imaging (metallic objects, pregnancy) or confounding factors for structural brain studies (regular medication, contraceptives, left handedness). Informed written consent was obtained from all participants after description of the study, which was approved by the ethics committee of the Canton of Bern, Switzerland (161/07) in accordance with the principles of the Declaration of Helsinki [18]. Written informed consent was obtained from the patient for publication of this report and any accompanying images. A copy of the written consent is available for review by the Editor-in-Chief of this journal.

\section{Diagnostic instruments and questionnaires}

Patients: Diagnoses for specific phobia for spider was based on the Diagnostic and Statistical Manual of Mental
Disorders, fourth edition (DSM-IV) [1]. Specifically, we used a computer-based structured clinical interview (DIA$\mathrm{X})$ [19] which is based on the Composite International Diagnostic Interview (CIDI) [20]. Patients were screened for possible axis II disorders, respectively personality accentuation using SKID-II-questionnaire [21]. The SKID-II is an efficient, user-friendly instrument that helps to make standardized, reliable, and accurate diagnoses of the 10 DSM-IV Axis II personality disorders.

Control subjects: SCL-90-R was used as short screening to exclude Axis-I disorders (such as anxiety disorders and depression) in the control subjects [22].

All subjects filled out the German version of the Spider Phobia Questionnaire (SPQ) [23] and a questionnaire for the assessment of disgust sensitivity (FEE) [24]. The SPQ is a validated self-report questionnaire widely used for assessing spider phobic symptom severity. It consists of 31 items which could be answered by "true" or "false" statements. Subjects with a SPQ (range 0-31) score of less than 21 "true" statements were treated as healthy controls. The FEE is a further development of the English Disgust Scale [25]. It is used to measure individual differences in sensitivity to disgust, and to examine the relationships among different kinds of disgust. Humans with a high disgust sensitivity show longer and more intensive disgust reactions than those with lower disgust sensitivity. Disgust sensitivity is treated as a vulnerability factor for the development and maintenance of disorders such as phobias. Participants had to rate how disgusted they feel when confronted with several stimuli on a five-points Likert-scale $(0=$ 'not disgusting at all' to $4=$ 'very disgusting'). A total score (range: 0-148) can be calculated which captures a measure for overall disgust sensitivity towards disgusteliciting stimuli. State (both groups) and trait anxiety (only in patient group) were measured using the German version of the State-Trait Anxiety Inventory (STAI) [26]. The STAI consists of two 20-item scales for measuring the anxiety intensity as an emotional state and individual differences in anxiety proneness as a personality trait. The STAI state reports the intensity of anxiety feelings at the moment of assessment. Responses to the STAI trait items requests subjects to indicate how they generally feel. Both scales range from 20 to 80 points. Handedness was assessed via the Edinburgh Handedness Inventory (EHI) [27].

\section{Data acquisition}

Magnetic resonance imaging was performed on a $3 \mathrm{~T}$ Siemens Magnetom Trio Scanner (Erlangen, Germany) equipped with a standard radio-frequency head coil. For structural images, a high-resolution 3D T1-weighted imaging protocol (modified driven equilibrium Fourier transform, MDEFT [28]) was used, resulting in 176 sagittal 
slices of $1.0 \mathrm{~mm}$ thickness, $256 \times 256 \mathrm{~mm}$ field of view (FOV), and a matrix size of $256 \times 256$, resulting in a voxel size of $1 \times 1 \times 1 \mathrm{~mm}$. Further scan parameters were $7.92 \mathrm{~ms}$ repetition time (TR) $2.48 \mathrm{~ms}$ echo time (TE) and $910 \mathrm{~ms}$ inversion time (Ti) for an optimal contrast-to-noise ratio (see [28]). Subjects were measured within their luteal phase of their menstrual cycle, because a study in healthy female subjects revealed an increase in AMV during the premenstrual phase compared to the late follicular phase [29].

\section{Segmentation of the amygdala}

For subcortical segmentation, a fully-automated segmentation method (FSL FIRST; http://fsl.fmrib.ox.ac.uk/fsl/ fslwiki/) was used [30], which has been shown to accurately segment subcortical structures [31]. The reliability for the segmentation of the amygdala by FIRST has been demonstrated and was correlated with those of manual tracing [32]. It is based on multivariate Gaussian shape/appearance models, which are constructed from a large set of manually labeled and segmented images (336 brains) from the Center for Morphometric Analysis (MGH, Boston) and uses a Bayesian framework that includes intra- and inter-structural variability. Using T1 images, the segmentation was performed with two stage affine transformation to standard space of MNI152 at $1 \mathrm{~mm}$ resolution. The first stage was a standard 12 degrees of freedom registration to the MNI152 template after which the normalization has been checked manually. The second stage applied 12 degrees of freedom registration using an MNI152 amygdala mask to exclude voxels outside this subcortical region. The segmented images were then used to produce mesh and volumetric outputs with boundary correction. Voxels exhibiting ambiguous structural characteristics, which are usually located at the borders between adjacent structures (partial volume effect), were classified as boundary voxels. The algorithm for the boundary correction requires the number of modes of variation (iterations) as input, which was set to 80 for the amygdalae (as recommended by Patenaude and colleagues [33]). The vertex information was then automatically transformed back to native space using the inverse transformation matrix where the boundaries were corrected. Finally, the summary images of the segmentation outputs were checked for quality and registration. Samples for the automatic segmentation of FIRST are shown in Figure 1.

\section{Brain volume measurement}

To correct for variations in individual's head size, the measured AMV were divided by the total intracranial volume (ICV). For each subject, the ICV was measured applying the software tool "BET" (Brain extraction tool) [34], provided as part of the FSL software distribution. The extracted voxels were then summed up to provide an estimate of the ICV.

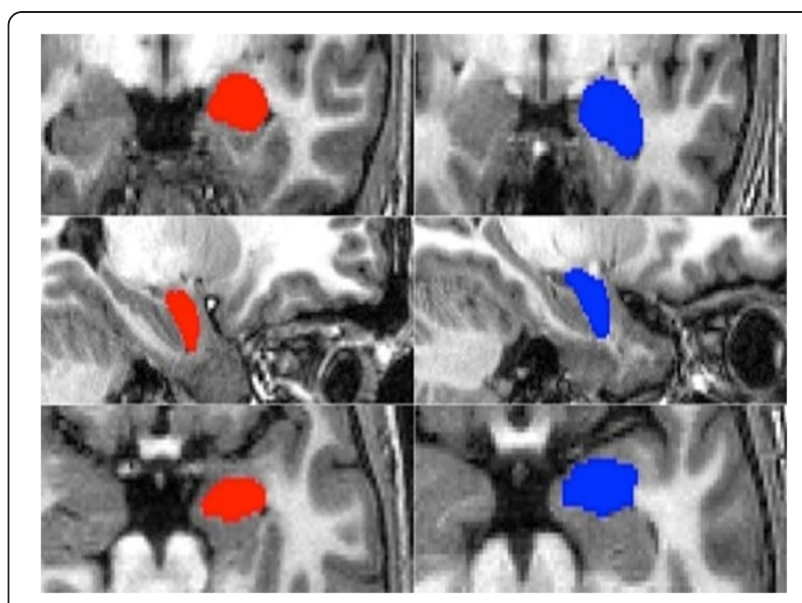

Figure 1 Segmentation sample. Example of the automatic amygdala segmentation with FSL_FIRST of one patient (red) and one control subject (blue): coronal, saggital, and axial views of the automatically set boundaries.

\section{Statistical analysis}

SPSS 19 software (SPSS Inc., Armonk, NY) was employed for statistical analyses. The following tests were used for the statistical analyses: two-sample independent t-tests to compare differences between groups for demographic, clinical and for brain volume variables; relative amygdala volume values (corrected for ICV) were used for the multifactorial ANCOVA with group as between-subject factor and left and right amygdala as the dependent factors; for the association between AMV and clinical features, we computed Spearman correlations and Wilcoxon's test was applied for comparisons of variables which were not normally distributed (SPQ and STAI state pre). In order to check whether the data is normally distributed, the Mauchly-Test of Sphericity was applied. The effects of BMI and age on AMV were examined with separate regression analyses with BMI or age as independent variables and left or right amygdala volume as dependent variables. For all statistical analyses, $\mathrm{p}$ values of $<.05$ (two-sided) were considered as significant results.

\section{Results}

\section{Demographic and psychological measures}

Patients and control subjects did not differ significantly with respect to any demographic variables (Table 1 ). The age of the subjects ranged from 20 to 54 years with a mean of 29.9 years in patient group $(S D \pm 11.3)$ and 27.1 years in control group ( $S D \pm 5.9)$. Group analysis revealed that patients showed significant higher mean scores on the SPQ (W=214.5, $\mathrm{Z}=-5.30, \mathrm{p}=0.00$ ). Furthermore, patients reported higher state anxiety (STAI-state) before scanning (which included also exposure to spiders; $W=211.00, Z=-1.97, p=0.05)$, but not after scanning $(F[3,36]=6.32 ; p=0.25)$, suggesting patients suffering from anticipatory anxiety. 
Table 1 Demographic and clinical characteristics of the patients and their control group

\begin{tabular}{|c|c|c|c|c|c|c|c|c|}
\hline \multirow[b]{2}{*}{ Characteristics } & \multicolumn{2}{|c|}{ Patients $(n=20)$} & \multicolumn{2}{|c|}{ Controls $(n=20)$} & \multirow[b]{2}{*}{ df } & \multirow[b]{2}{*}{$\mathbf{t}$} & \multirow[b]{2}{*}{$\mathbf{p}$} & \multirow[b]{2}{*}{$\begin{array}{c}\text { Equality of } \\
\text { variance }\end{array}$} \\
\hline & Mean & SD & Mean & SD & & & & \\
\hline Age (years) & 29.9 & 11.3 & 27.1 & 5.9 & 38 & -0.98 & 0.33 & 0.91 \\
\hline Age at onset & 6.65 & 3.28 & 一一 & -二-二- & - & 一 & -一 & - \\
\hline Duration of illness (years) & 22.14 & 13.01 & - & - & & & & 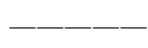 \\
\hline Handedness scores & 9.7 & 0.58 & 9.8 & 0.41 & 38 & 0.65 & 0.52 & 0.98 \\
\hline SPQ & 21.55 & 4.29 & 6.1 & 3.83 & 38 & -11.99 & 0.00 & 0.00 \\
\hline FEE & 85.3 & 22.93 & 73 & 26.42 & 38 & -1.47 & 0.15 & 0.17 \\
\hline STAl state pre / post scanning & $39.85 / 34.85$ & $10.67 / 12.9$ & $32.5 / 30.53$ & $4.05 / 6.61$ & 38 & $-2.51 /-1.18$ & $0.05 / 0.24$ & $0.05 / 0.54$ \\
\hline STAI trait & 44.8 & 6.89 & -———- & -二-二- & -一- & - & 一——— & 一一一 \\
\hline BMI & 21.8 & 3.90 & 21.63 & 2.31 & 38 & -1.18 & 0.87 & 0.61 \\
\hline
\end{tabular}

SPQ: Spider Phobia Questionnaire; FEE: disgust sensitivity scale; BMI: body mass index.

\section{Amygdala volume}

Multifactorial ANCOVA of AMV, adjusted for ICV, showed approximately $13 \%$ smaller AMV in patients on the left than in controls, resulting in a significant between group effect for left $\operatorname{AMV}(F[3,36]=6.39 ; p=0.02$; Figure $2 \mathrm{a})$. Separate regression analyses indicated that the difference in left AMV between patients and controls were not accounted for by differences in age $(F=1.72$; $d f=36$, $p=0.20)$ and BMI $(F=0.55, d f=36, p=0.47)$. There was no significant difference of right AMV between patients and controls $(F[3,36]=2.28 ; p=0.20$; Figure $2 b)$. Within the whole group, SPQ scores were negatively correlated with left AMV ( $r=-0.47 ; p=0.005$; Figure 3$)$. Separate regression analyses showed that smaller left amygdala occurred independently of age $(r=-0.046 ; p=0.79)$ and BMI $(r=-0.143$; $p=0.42$ ). Correlations between left amygdala and the disgust score (FEE) or state anxiety (STAI trait/state) did not reach significance, nor were there any significant correlations between right AMV and clinical scores within the whole sample. Within the phobic sample, trait anxiety did not correlate with AMV. Thus, differences in AMV did not appear to be due to age or BMI or clinical features of the participants.

\section{Discussion}

The purpose of this study was to determine whether there is evidence for AMV differences in patients with spider phobia compared to healthy controls. As hypothesized, the findings confirm a reduction in left AMV of patients. Furthermore, the reduced left AVM is associated with the severity of spider phobic symptoms. Our finding of abnormal left AMV in patients are consistent with findings that report diminished amygdala size in fear and anxietyrelated disorders [10,35-40]. We suggest that the automatic manifestation of fear responses is mediated by a
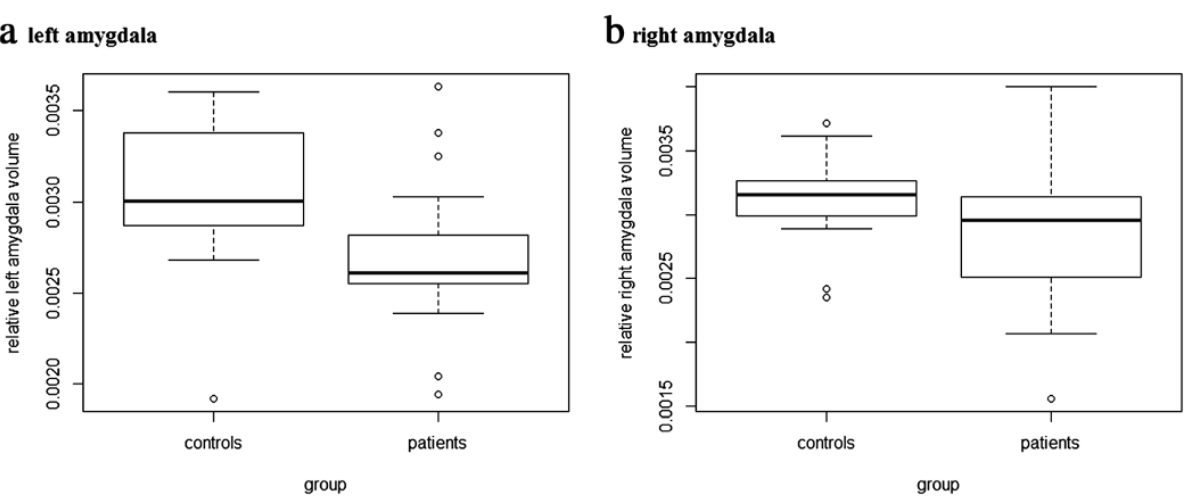

Figure 2 Amygdala volumes of spider phobic patients and healthy controls. The central box shows the data between $25^{\text {th }}$ and $75^{\text {th }}$ quartiles, with the median represented by the line. The whiskers extend from the upper and lower quartiles to a distance of 1.5 interquartile range (IQR). Circles represent the outliers over $3 \mathrm{IQR}$ below the $25^{\text {th }}$ or above the $75^{\text {th }}$ quartile. Relative amygdala volumes were calculated by the following formula: 100x(absolute amygdala volume in $\mathrm{mm}^{2}$ /intracranial volume in $\mathrm{mm}^{2}$ ). a: boxplot comparing relative left amygdala volume; b: boxplot comparing relative right amygdala volume. 

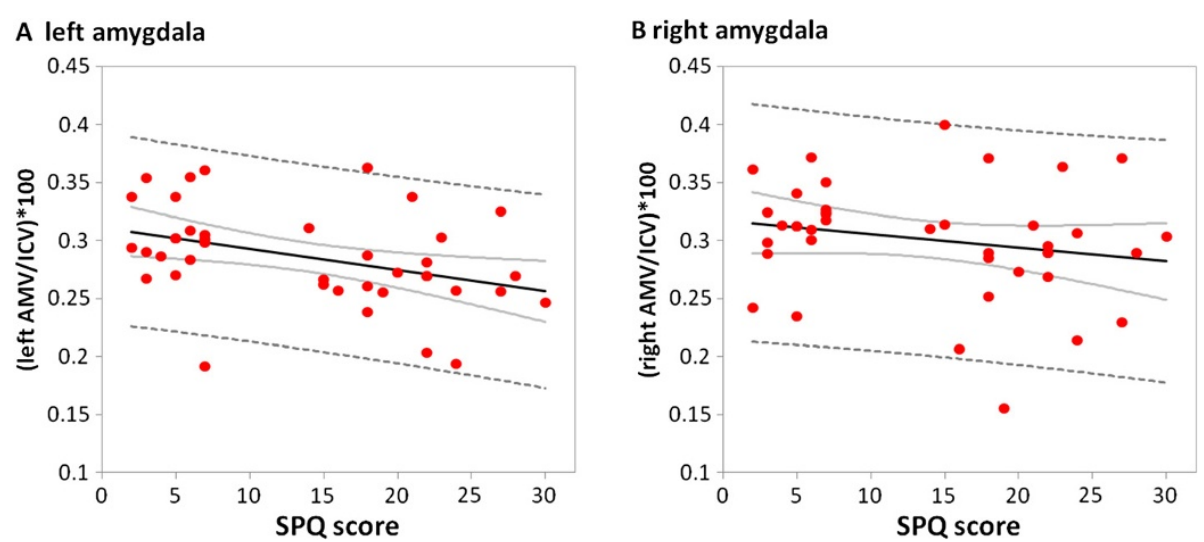

Figure 3 Relation between the amygdalae and Spider Phobia Questionnaire (SPQ) scores. A: The scores on the SPQ are negatively correlated with the left amygdala volume $(r=-0.425, p=0.011)$. More phobic symptoms are found in individuals who have smaller left amygdala. B: The volumes of the right amygdala are not significantly correlated with SPQ Scores.

potentiated fear network which may be associated with an amygdala deficiency.

However, the differences of AMV could be also influenced by clinical factors. The present findings show an association between left AMV and symptom severity in phobic patients in the way that the smaller the left amygdala, the more phobic symptoms they reported. This finding seems to be attributed to spider phobia, because we selected patients with pure spider phobia without any comorbidities and no other potential confounding factor has shown to be associated with this volume reduction in spider phobic patients. It is worth remarking that findings of smaller left AMV, as reported in this study, suggest that abnormal functioning of this structure may underlie the symptoms of automatic and exaggerated fear response observed in specific phobias, as measured with the SPQ, which reliably assesses fear of spiders [41,42].

Hemispheric differences in amygdala alterations found in this study may potentially be in line with different roles in emotion processing for the left and right amygdala which has been found in several studies investigating mood and anxiety disorders $[39,43]$. Based on these studies, it is assumed that the left amygdala is more involved in processing sustained stimulus evaluation while the right one is more involved in rapid and undifferentiated processing of emotional stimuli [44].

Some limitations of the present study need to be mentioned. We only studied female subjects; therefore the results cannot be generalized to men. We should further mention the different diagnostic measurements for the control and patient group. The patient group was additionally screened for possible personality disorders (SKID-II) and trait-anxiety (STAI-trait). Whereas the control subjects were only screened for possible axis I-disorders (SCL-90-R) which implied exclusion of the study. Additionally, the sample size was modest and should be extended. However, the patient group can be considered to be homogenous, as patients did not suffer from any other axis I disorders at the time of assessment. Hence, future investigations should include comparisons of amygdala morphology in various types and degrees of phobic disorders for a better pathophysiological distinction. Longitudinal and pre-post treatment studies should clarify the meaning of the observed amygdala differences over time.

\section{Conclusion}

Still, the reasons for volumetric differences are so far largely unclear. Two possible interpretations might be offered: First, smaller left AMV might be a vulnerability factor for the development of spider phobia. The second interpretation relates to experience or exposure-related structural modifications within the amygdala. Whether the observed atrophy of the amygdala in mood and anxiety disorders is progressive and already present at time of disease onset or develops as a result of damage secondary to higher amygdala activity is a matter of debate $[45,46]$.

\section{Abbreviations \\ AMV: Amygdala volume; ANCOVA: Analysis of covariance; BMl: Body mass index; EHI: Edinburgh handedness inventory; FEE: Questionnaire for the assessment of disgust sensitivity; FOV: Field of view; ICV: Intracranial volume; SD: Standard deviation; SP: Spider phobic patients; SKID-II: Structured clinical interview for DSM-IV Axis II disorders; SPQ: Spider phobia questionnaire; STAI: State-trait anxiety inventory.}

\section{Competing interests}

The authors declare that they have no competing interests.

\section{Authors' contribution}

MF participated in the design of the study, carried out the measurements, performed the statistical analysis and drafted the manuscript. AF carried out the sequence alignment and revised the manuscript critically. $\mathrm{HH}$ participated in the diagnostic interview and revised the manuscript critically. TD revised the manuscript critically. WS participated in the diagnostic interviews. DQ made the conception and design of the study and revised 
the manuscript critically. LS participated in the design of the study and revised the manuscript. All authors read and approved the final manuscript.

\section{Acknowledgements}

This work was funded by a grant from the Swiss National Science foundation (32003B_124947) and a grant from the Medical Faculty of the University of Berne (520.10). We thank B.Sc. Joëlle Witmer, lic. phil. Yvonne Renevey, M.Sc Céline de Buman, B.Sc. Susanne Hess, B.Sc. Basil Preisig, B.Sc. Vera Bamert, B. Sc. Esther Mahlstein, B.Sc. Isabelle Zogg and B.Sc. Veryan Thommen for research assistance.

\section{Author details}

'Department of Psychiatric Neurophysiology, University Hospital of Psychiatry, University of Bern, Bolligenstrasse 111 3000, Bern 60, Switzerland. ${ }^{2}$ Diagnostic and Interventional Neuroradiology, Inselspital and University of Bern, OP-Ost C215, Bern 3010, Switzerland. ${ }^{3}$ Division of Cognitive Neuroscience, Faculty of Medicine \& Faculty of Psychology, University of Basel, Birmannsgasse 8 4055, Basel, Switzerland.

Received: 18 May 2012 Accepted: 20 February 2013 Published: 26 February 2013

\section{References}

1. American Psychiatric Association: Diagnostic and statistical manual of mental disorders (4th ed., text rev.). Washington, DC: Author.) 2000:188-190.

2. Ohman A, Mineka S: Fears, phobias, and preparedness: toward an evolved module of fear and fear learning. Psychol Rev 2001, 108(3):483-522.

3. Schienle A, SchÃafer A, Walter B, Stark R, Vaitl D: Brain activation of spider phobics towards disorder-relevant, generally disgust- and fear-inducing pictures. Neurosci Lett 2005, 388(1):1-6.

4. Straube T, Mentzel H-J, Miltner WHR: Neural mechanisms of automatic and direct processing of phobogenic stimuli in specific phobia. Biol Psychiatry 2006, 59(2):162-170.

5. Etkin A, Wager TD: Functional neuroimaging of anxiety: a meta-analysis of emotional processing in PTSD, social anxiety disorder, and specific phobia. Am J Psychiatry 2007, 164(10):1476-1488.

6. Phelps EA, LeDoux JE: Contributions of the amygdala to emotion processing: from animal models to human behavior. Neuron 2005, 48(2):175-187.

7. Veening JG, Swanson LW, Sawchenko PE: The organization of projections from the central nucleus of the amygdala to brainstem sites involved in central autonomic regulation: a combined retrograde transportimmunohistochemical study. Brain Res 1984, 303(2):337-357.

8. Freese $J L$, Amaral $D G$ : The organization of projections from the amygdala to visual cortical areas TE and V1 in the macaque monkey. J Comp Neurol 2005, 486(4):295-317.

9. Drevets W, Price J, Furey M: Brain structural and functional abnormalities in mood disorders: implications for neurocircuitry models of depression. Brain Struct Funct 2008, 213(1):93-118.

10. Anand A, Shekhar A: Brain imaging studies in mood and anxiety disorders. Ann N Y Acad Sci 2003, 985(1):370-388.

11. Drevets WC: Neuroimaging abnormalities in the amygdala in mood disorders. Ann N Y Acad Sci 2003, 985(1):420-444.

12. Brambilla P, Barale F, Caverzasi E, Soares JC: Anatomical MRI findings in mood and anxiety disorders. Epidemiol Psichiatr Soc 2002, 11(2):88-99.

13. Blackmon K, Barr WB, Carlson C, Devinsky O, Dubois J, Pogash D, Quinn BT, Kuzniecky R, Halgren E, Thesen T: Structural evidence for involvement of a left amygdala-orbitofrontal network in subclinical anxiety. Psychiatry Res 2011, 194(3):296-303.

14. Spampinato MDM, Wood PDJ, De Simone MDV, Grafman PDJ: Neural correlates of anxiety in healthy volunteers: a voxel-based morphometry study. J Neuropsychiatry Clin Neurosci 2009, 21(2):199-205.

15. Hayano F, Nakamura M, Asami T, Uehara K, Yoshida T, Roppongi T, Otsuka T, Inoue T, Hirayasu Y: Smaller amygdala is associated with anxiety in patients with panic disorder. Psychiatry Clin Neurosci 2009, 63(3):266-276.

16. Clark LA, Watson D, Mineka S: Temperament, personality, and the mood and anxiety disorders. Journal of Abnormal Psychology J Abnorm Psychol 1994, 103(1):103-116.
17. Chambers JA, Power KG, Durham RC: The relationship between trait vulnerability and anxiety and depressive diagnoses at long-term followup of generalized anxiety disorder. J Anxiety Disord 2004, 18(5):587-607.

18. Rickham PP: Human experimentation. Code of ethics of the world medical association. Declaration of helsinki. Br Med J 1964, 2(5402):177. 2

19. Essau CA, Wittchen HU, Pfister H: DIA-X-Interview. Diagnostica 1999, 45(3):163-164

20. Rubio-Stipec M, Bravo M, Canino G: [The composite international diagnostic interview (CIDI): an epidemiologic instrument suitable for using in conjunction with different diagnostic systems in different cultures]. Acta Psiquiatr Psicol Am Lat 1991, 37(3):191-204.

21. Fydrich T, Renneberg B, Schmitz B, Wittchen H-U: SKID-II: strukturiertes klinisches interview für DSM-IV, achse II: persönlichkeitsstörungen. Göttingen: Hogrefe; 1997.

22. Franke $\mathrm{G}$, Stacker $\mathrm{KH}$ : Reliability and validity of the symptom checklist (SCL-90-R, derogatis, 1986) in standardized versus homogenous itemblocked sequence. Diagnostica 1995, 41(4):349-373.

23. Klorman R, Weerts TC, Hastings JE, Melamed BG, Lang PJ: Psychometric description of some specific-fear questionnaires. Behav Ther 1974, 5(3):401-409.

24. Schienle A, Walter B, Stark R, Vaitl D: Ein fragebogen zur erfassung der ekelempfindlichkeit (FEE). Z KI Psych Psychoth 2002, 31(2):110-120.

25. Olatunji BO, Cisler JM, Deacon BJ, Connolly K, Lohr JM: The disgust propensity and sensitivity scale-revised: psychometric properties and specificity in relation to anxiety disorder symptoms. J Anxiety Disord 2007, 21(7):918-930.

26. Spielberger CD, Gorsuch RL, Lushene RE: Manual for state-trait anxiety inventory (self-evaluation questionnaire). Palo Alto, CA: Consulting Psychologists Press; 1970.

27. Oldfield RC: The assessment and analysis of handedness: the Edinburgh inventory. Neuropsychologia 1971, 9(1):97-113.

28. Deichmann R, Schwarzbauer C, Turner R: Optimisation of the 3D MDEFT sequence for anatomical brain imaging: technical implications at 1.5 and 3 T. Neurolmage 2004, 21(2):757-767.

29. Ossewaarde L, van Wingen GA, Kooijman SC, Backstrom T, Fernandez G, Hermans EJ: Changes in functioning of mesolimbic incentive processing circuits during the premenstrual phase. Soc Cogn Affect Neur 2011, 6(5):612-620.

30. Patenaude B: Bayesian statistical models of shape and appearance for subc ortical brain segmentation. Oxford: University of Oxford; 2007.

31. Babalola K, Patenaude B, Aljabar P, Schnabel J, Kennedy D, Crum W, Smith $\mathrm{S}$, Cootes $\mathrm{T}$, Jenkinson $\mathrm{M}$, Rueckert $\mathrm{D}$, et al: Comparison and evaluation of segmentation techniques for subcortical structures in brain MRI medical image computing and computer-assisted intervention - MICCAI 2008, Volume Volume 5241. Heidelberg: Springer Berlin; 2008:409-416.

32. Morey RA, Petty CM, Xu Y, Pannu Hayes J, Wagner li HR, Lewis DV, LaBar KS, Styner M, McCarthy G: A comparison of automated segmentation and manual tracing for quantifying hippocampal and amygdala volumes. Neurolmage 2009, 45(3):855-866.

33. Patenaude B, Smith SM, Kennedy DN, Jenkinson M: A Bayesian model of shape and appearance for subcortical brain segmentation. Neurolmage 2011, 56(3):907-922.

34. Smith SM: Fast robust automated brain extraction. Hum Brain Mapp 2002, 17(3):143-155

35. Milham MP, Nugent AC, Drevets WC, Dickstein DS, Leibenluft E, Ernst M, Charney D, Pine DS: Selective reduction in amygdala volume in pediatric anxiety disorders: a voxel-based morphometry investigation. Biol Psychiatry 2005, 57(9):961-966.

36. Szeszko PR, Robinson D, Alvir JMJ, Bilder RM, Lencz T, Ashtari M, Wu H, Bogerts B: Orbital frontal and amygdala volume reductions in obsessivecompulsive disorder. Arch Gen Psychiatry 1999, 56(10):913-919.

37. MacMaster FP, Mirza Y, Szeszko PR, Kmiecik LE, Easter PC, Taormina SP, Lynch M, Rose M, Moore GJ, Rosenberg DR: Amygdala and hippocampal volumes in familial early onset major depressive disorder. Biol Psychiatry 2008, 63(4):385-390.

38. Sheline YI, Barch DM, Price $J$, Rundle MM, Vaishnavi SN, Snyder AZ, Mintun MA, Wang S, Coalson RS, Raichle ME: The default mode network and selfreferential processes in depression. Proc Natl Acad Sci USA 2009, 106(6):1942-1947.

39. Pearlson GD, Barta PE, Powers RE, Menon RR, Richards SS, Aylward EH, Federman EB, Chase GA, Petty RG, Tien AY: Medial and superior temporal 
gyral volumes and cerebral asymmetry in schizophrenia versus bipolar disorder. Biol Psychiatry 1997, 41(1):1-14.

40. Massana G, Serra-Grabulosa JM, Salgado-Pineda P, Gasto C, Junque C, Massana J, Mercader JM, Gomez B, Tobena A, Salamero M: Amygdalar atrophy in panic disorder patients detected by volumetric magnetic resonance imaging. Neurolmage 2003, 19(1):80-90.

41. Rinck M, Bundschuh S, Engler S, Muller A, Wissmann J, Ellwart T, Becker ES: Reliability and validity of German versions of three instruments measuring fear of spiders. Diagnostica 2002, 48(3):141-149.

42. Muris $\mathrm{P}$, Merckelbach $\mathrm{H}$ : A comparison of two spider fear questionnaires. J Behav Ther Exp Psychiatry 1996, 27(3):241-244.

43. Sheline $\mathrm{YI}$, Sanghavi M, Mintun MA, Gado MH: Depression duration but not age predicts hippocampal volume loss in medically healthy women with recurrent major depression. J Neurosci 1999, 19(12):5034-5043.

44. Straube T, Mentzel HJ, Miltner WH: Neural mechanisms of automatic and direct processing of phobogenic stimuli in specific phobia. Biol Psychiatry 2006, 59(2):162-170.

45. Hettema JM, Kettenmann B, Ahluwalia V, McCarthy C, Kates WR, Schmitt JE, Silberg JL, Neale MC, Kendler KS, Fatouros P: Pilot multimodal twin imaging study of generalized anxiety disorder. Depress Anxiety 2012, 29(3):202-209.

46. van der Plas EA, Boes AD, Wemmie JA, Tranel D, Nopoulos P: Amygdala volume correlates positively with fearfulness in normal healthy girls. Soc Cogn Affect Neurosci 2010, 5(4):424-431.

doi:10.1186/1471-244X-13-70

Cite this article as: Fisler et al: Spider phobia is associated with decreased left amygdala volume: a cross-sectional study. BMC Psychiatry 2013 13:70.

\section{Submit your next manuscript to BioMed Central and take full advantage of:}

- Convenient online submission

- Thorough peer review

- No space constraints or color figure charges

- Immediate publication on acceptance

- Inclusion in PubMed, CAS, Scopus and Google Scholar

- Research which is freely available for redistribution 